\title{
COMPOSIÇÃO FLORÍSTICA E FITOGEOGRAFICA DE UMA FLORESTA ATLÂNTICA NO SUDESTE BRASILEIRO
}

\author{
Vinicius Costa Cysneiros ${ }^{1}$; Denise Monte Braz²; Allan Libanio Pelissari³ ${ }^{3}$ Kênia Samara Mourão \\ Santos 4 \\ $1^{*}$ Universidade Federal do Paraná, Pós-graduação em Engenharia Florestal, Curitiba, Paraná, Brasil, \\ vccysneiros.florestal@gmail.com \\ ${ }^{2}$ Universidade Federal Rural do Rio de Janeiro, Departamento de Botânica, Seropédica, Rio de Janeiro, Brasil, \\ dmbraz@ufrri.br \\ ${ }^{3}$ Universidade Federal do Paraná, Departamento de Ciências Florestais, Curitiba, Paraná, Brasil, allanpelissari@gmail.com \\ ${ }^{4}$ Universidade Federal do Paraná, Pós-graduação em Engenharia Florestal, Curitiba, Paraná, Brasil, \\ keniasmsantos@outlook.com
}

\begin{abstract}
Resumo
O objetivo do presente estudo foi analisar a distribuição geográfica das espécies arbóreas e investigar a influência da proximidade entre florestas ombrófilas e estacionais na composição da flora local, por meio de análise de agrupamento e similaridade. Fabaceae, Lauraceae, Myrtaceae, Rubiaceae, Moraceae e Sapotaceae foram as famílias mais ricas em espécies. Contudo, o nível de endemismo encontrado foi de $36,5 \%$, considerado baixo, quando comparado com outros estudos realizados na Mata Atlântica. A análise de similaridade evidenciou a existência de cinco grupos, formados por características ambientais e composição de espécies semelhantes, demonstrando que altitude e a pluviosidade são fatores determinantes na distribuição das espécies e na composição das floras.
\end{abstract}

Palavras-chave: Endemismo; Similaridade; Análise de agrupamento.

\begin{abstract}
Floristic and phytogeographic compositions of an Atlantic Forest in Brazilian Southeast. The aim of this study was to analyze the geographical distribution of tree species and investigate the influence of proximity between rainforests and seasonal forests in the composition of local flora through cluster analysis and similarity. Fabaceae, Lauraceae, Myrtaceae, Rubiaceae, Moraceae and Sapotaceae were the richest families in species. However, endemism level found was $36.5 \%$, considered low when compared to other studies in the Atlantic Forest. The similarity analysis showed that there are five groups, formed by environmental characteristics and composition of similar species, demonstrating that altitude and pluviosity are key factors in species distribution and composition of flora.
\end{abstract}

Keywords: Endemism; Similarity; Cluster analysis.

\section{INTRODUÇÃO}

A floresta atlântica originou da separação do supercontinente Gondwana, no continente africano e sul americano, durante o final do Cretáceo até o início do Quaternário (BIGARELLA, 1991; PEIXOTO et al., 2002; FERREIRA JÚNIOR et al., 2009), cuja paisagem montanhosa e a complexidade de eventos geomorfológicos, climáticos e biológicos, também são explicados por esses fatores tectônicos, sendo o testemunho histórico da evolução dessa paisagem. As oscilações climáticas, entre os períodos secos e úmidos, ocorridas nos últimos dois milhões de anos, também desempenharam influência marcante no desenvolvimento dessa paisagem, atuando na formação do atual quadro fitogeográfico (PEIXOTO et al., 2002; FERREIRA JÚNIOR et al., 2009). Assim, a Fitogeografia se encontra intimamente dependente da história de evolução das floras, uma vez que a atual disjunção entre as florestas tropicais nem sempre existiu (MORLEY, 2000; PUIG, 2008).

Mesmo isolada dos blocos florestais Amazônicos e Andinos, devido à existência do corredor de vegetação seca, composto pelo Cerrado, Caatinga e Chaco (BIGARELLA, 1975; AB'SABER, 1990; OLIVEIRA FILHO; RATTER, 2004), a Floresta Atlântica já esteve interligada a esses blocos no passado 
(MORLEY, 2000). Essa interligação pode ser confirmada tanto pela presença de espécies comuns aos blocos florestais e as matas de galeria do corredor de vegetação seca (OLIVEIRA FILHO; FONTES, 2000; OLIVEIRA FILHO; RATTER, 2004; AMORIM et al., 2008) quanto pela presença de elementos compartilhados entre e a Floresta Amazônica e a Floresta Atlântica de Tabuleiros (AMORIM et al., 2008), evidenciando uma ligação pretérita e atual dessas florestas (OLIVEIRA FILHO; RATTER, 2004).

Estudos de similaridade florística e fitogeográfica realizados na Floresta Atlântica têm evidenciado maior semelhança em trechos de mesma formação e elevada heterogeneidade ao longo do bioma (TORRES et al., 1997; MORENO et al., 2003; PEIXOTO et al., 2005; NETTESHEIM et al., 2010). As técnicas de análise multivariada, por possibilitarem a visualização de padrões ecológicos em dados florísticos, permitiram constatar importantes características do bioma, como a diferenciação ou semelhança de acordo com características climáticas, geomorfológicas e geográficas (OLIVEIRA FILHO; FONTES, 2000; NETTESHEIM et al., 2010).

Segundo Eisenlohr et al. (2011), uma peculiaridade do Sudeste brasileiro é a presença de remanescentes de diferentes formações ocorrendo próximas e em baixa amplitude latitudinal. Assim, visto que as variáveis geográficas e ecológicas mantêm forte correlação com os padrões florísticos (OLIVEIRA FILHO; RATTER, 2004), os estudos fitogeográficos realizados com o auxílio de análises de agrupamento e de similaridade assumem relevância na caracterização das formações florestais de acordo com critérios florísticos.

Dessa forma, o presente estudo tem como objetivo analisar a distribuição geográfica das espécies arbóreas e verificar a influência da proximidade entre as florestas ombrófilas e estacionais na composição da flora local, considerando a hipótese que o clima e a localização geográfica são os fatores determinantes na composição das floras.

\section{MATERIAL E MÉTODOS}

\section{Área de estudo}

O Parque Natural Municipal do Curió está localizado no município de Paracambi, estado do Rio

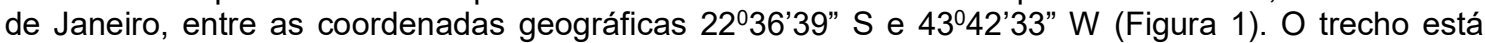
inserido no bioma Floresta Atlântica, abrangendo as formações Floresta Ombrófila Densa Sub-Montana e Montana (VELOSO et al., 1991), com altitudes variando de 50 a $690 \mathrm{mnm}$. O clima local, segundo a classificação de Köppen, está enquadrado como Aw, variando entre brando subtropical e tropical quente/úmido, com temperatura média anual de $23,4^{\circ} \mathrm{C}$ e precipitação média entorno de $1.050 \mathrm{~mm}$ (PEEL et al., 2007).
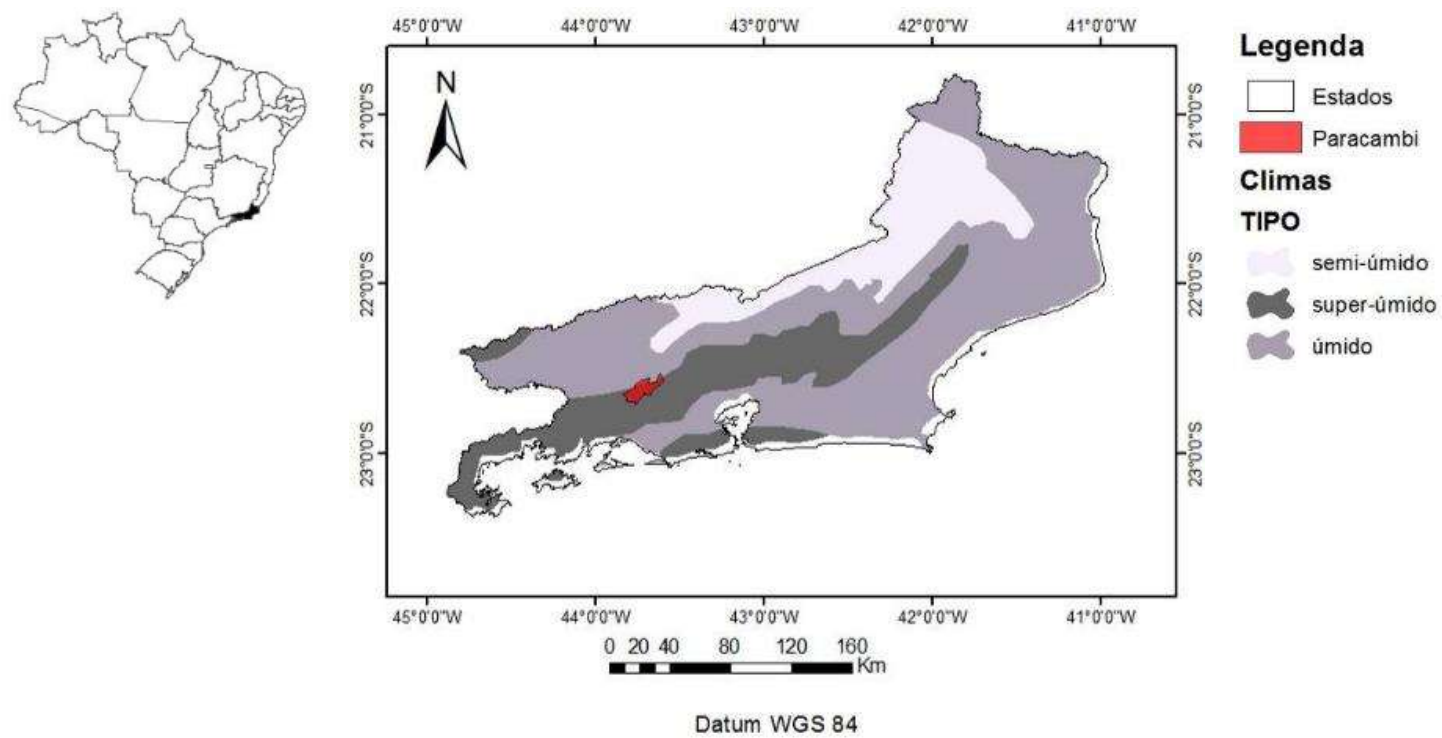

Figura 1. Localização geográfica e climática do município de Paracambi - RJ.

O Parque Natural Municipal do Curió está localizado no Corredor Sul da Floresta Atlântica, no 
Corredor Bocaina-Tinguá (SMMAP; ITPA, 2010) e no Mosaico da Mata Atlântica Central Fluminense (LINO; ALBUQUERQUE, 2007). Inserido na formação geomorfológica Serras e Morros Altos, possui relevo variando de fortemente ondulado nas partes mais elevadas e de planícies nas áreas de baixada (AMORIM, 2012), apresentando, em alguns trechos, grande quantidade de afloramentos rochosos e solos rasos. Quanto às classes e níveis categóricos de solos, predominam na região os Argissolos Vermelho-Amarelos Distróficos e Vermelho Eutróficos e o Latossolo Vermelho-Amarelos Distróficos.

\section{Análise dos dados}

A lista de espécies utilizada foi obtida com base no levantamento fitossociológico contido em Cysneiros et al. (2015). Dessa lista, foram utilizados apenas os 189 táxons classificados ao nível específico. Assim, por meio de bibliografia especializada, foram obtidas informações de formações florestais e de biomas de ocorrência das espécies (STEHMANN et al., 2009; FORZZA et al., 2015).

Para a análise de similaridade, foram selecionados 15 estudos florísticos realizados no estado do Rio de Janeiro (Tabela 1), em diferentes formações florestais. O nome das espécies foi revisado por meio da base de dados Tropicos do Missouri Botanical Garden, com o objetivo de evitar sinonímias e erros na sua distribuição. O sistema de classificação adotado seguiu o Angyosperm Phylogeny Group (APG, 2009).

Tabela 1. Parâmetros geográficos, ambientais e florísticos das áreas utilizadas para a análise fitogeográfica de agrupamento

\begin{tabular}{|c|c|c|c|c|c|c|c|}
\hline Local & $\begin{array}{l}\text { Formação } \\
\text { Florestal }\end{array}$ & $\begin{array}{l}\text { Altitude } \\
(\mathrm{m})\end{array}$ & $\begin{array}{c}\text { Temperatura } \\
\left({ }^{\circ} \mathrm{C}\right)\end{array}$ & $\begin{array}{l}\text { Pluviosidade } \\
\text { (mm) }\end{array}$ & Famílias & Espécies & $\begin{array}{l}\text { Indice de } \\
\text { Shannon }\end{array}$ \\
\hline PNM do Curió (PMC) ${ }^{1}$ & FODSM & 390 & 23,4 & 1.050 & 51 & 210 & 4,70 \\
\hline Porangaba $(\mathrm{POR})^{2}$ & FODSM & - & 22,3 & 1.224 & 36 & 105 & 3,80 \\
\hline Rio Bonito $(\mathrm{RBT})^{3}$ & FODS & 150 & - & 1.750 & 32 & 106 & 3,90 \\
\hline Visconde de Mauá (VMA) ${ }^{4}$ & FODM & 1.250 & 16,6 & 2.459 & 68 & 191 & - \\
\hline Campos dos Goytacaz (CAM) ${ }^{5}$ & FSTB & 50 & - & 1.023 & 35 & 105 & 4,02 \\
\hline Paraíso (PAR) ${ }^{6}$ & FODS & 60 a 1.350 & 23 & 2.558 & 42 & 138 & 4,20 \\
\hline Tinguá $(\mathrm{TIN})^{7}$ & FODM & 730 & 21,6 & 2.099 & 21 & 53 & 3,42 \\
\hline Itatiaia (ITA) ${ }^{8}$ & FODM & 800 & 19 & 1.765 & 65 & 117 & - \\
\hline Volta Redonda $(\mathrm{VR})^{9}$ & FODSM & 360 & 20,5 & 1.370 & - & 135 & 3,66 \\
\hline Bananal $(\mathrm{BAN})^{10}$ & FODM & 1.550 & 17 & 1.455 & - & 105 & - \\
\hline Médio Paraíba do Sul (MPS) ${ }^{11}$ & FES & 700 & - & 1.285 & 31 & 85 & 2,29 \\
\hline Capoeira Grande $(\mathrm{CG})^{12}$ & FODTB & - & 23,6 & 1.027 & 29 & 69 & 2,42 \\
\hline Ribeirão das Lages $(\mathrm{RL})^{13}$ & FODSM & 400 & 17,5 & 1.717 & 16 & 209 & - \\
\hline Mata do Carvão $(M C)^{14}$ & FSTB & 50 & - & 1.023 & 34 & 83 & 3,21 \\
\hline Imbé $(\mathrm{IMB})^{15}$ & FODS & $50 / 250$ & 22 & 1.300 & 39 & 210 & 4,30 \\
\hline
\end{tabular}

Em que: FODSM = Floresta Ombrófila Densa Sub Montana; FODM = Floresta Ombrófila Densa Montana; FSTB = Floresta Estacional Semidecidual de Terras Baixas; e FES = Floresta Estacional Semidecidual Sub Montana. Fonte: ${ }^{1}$ Cysneiros et al. (2015); ${ }^{2}$ Gandra et al. (2011); ${ }^{3}$ Carvalho et al. (2007); ${ }^{4}$ Pereira et al. (2007); ${ }^{5}$ Carvalho et al. (2006); ${ }^{6}$ Kurtz e Araújo (2000); ${ }^{7}$ Sobrinho et al. (2010); ${ }^{8}$ Pereira et al. (2007); ${ }^{9}$ Souza (2002); ${ }^{10}$ Castro (2001); ${ }^{11}$ Spolidoro (2001); ${ }^{12}$ Peixoto et al. (2004); ${ }^{13}$ Peixoto et al. (1995); ${ }^{14}$ Silva e Nascimento (2001); e ${ }^{15}$ Moreno et al. (2003).

Essas informações foram ordenadas na forma de duas matrizes binárias. Na primeira constou a presença ou a ausência das espécies em diferentes formações florestais. As espécies encontradas nos levantamentos citados foram ordenadas na forma de uma segunda matriz, onde constou a presença ou a ausência das espécies arbóreas nos 15 levantamentos e no Parque Natural Municipal do Curió. As espécies que ocorrem em apenas em uma das áreas analisadas foram excluídas da matriz.

A partir da primeira matriz binária, diagramas de Venn (OLIVEIRA FILHO; FONTES, 2000) foram construídos com objetivo de verificar o número de espécies exclusivas ou compartilhadas entre as formações. A similaridade florística com outras áreas foi avaliada por meio de análise de agrupamento e expressa na forma de dendrograma, utilizando-se o índice qualitativo de Sorensen 
(MAGURRAN, 2011) e o método Unweighted Pair Group Method Using Arithmetic Averages (UPGMA) de distância média de grupo (MCCUNE; GRACE, 2002), para verificar a existência de grupos similares em termos florísticos com auxílio do pacote estatístico R v. 3.2.2.

\section{RESULTADOS E DISCUSSÃO}

As espécies encontradas estão distribuídas em 51 famílias botânicas, sendo Fabaceae a mais rica (27 espécies; 14,3\%), seguida de Lauraceae (17; 8,9\%), Myrtaceae (14; 7,4\%), Rubiaceae (10; $5,3 \%)$, Moraceae $(10 ; 5,3 \%)$, Sapotaceae $(9 ; 4,7 \%)$ e Euphorbiaceae $(8 ; 4,2 \%)$. Na Floresta Atlântica, a riqueza das famílias citadas no presente estudo é conhecida, uma vez que Oliveira Filho e Fontes (2000), ao analisarem a florística de diversas áreas no Sudeste brasileiro, destacaram a riqueza e a diversidade de espécies das famílias Myrtaceae, Fabaceae, Lauraceae, Rubiaceae e Melastomataceae para Florestas Ombrófilas, com variações conforme a altitude. Nas Florestas Ombrófilas do estado do Rio de Janeiro, Carvalho et al. (2008) também encontraram Fabaceae, Lauraceae e Myrtaceae como as principais famílias em termos de riqueza.

No entanto, Fabaceae, a família mais rica do presente estudo, foi citada por Oliveira Filho e Fontes (2000) como a mais rica apenas em Florestas Estacionais Semideciduais, assim como observado por Ribeiro e Lima (2009), que destacaram a riqueza da família em Florestas Estacionais Submontanas. Esse fato está associado à capacidade de adaptação das espécies dessa família em solos de baixa fertilidade, devido à associação com bactérias fixadoras de nitrogênio (CAMPELLO, 1997; RIBEIRO; LIMA, 2009), o que favorece sua maior diversificação em ambientes estacionais (LEWIS et al., 2005). Tais trabalhos evidenciam um padrão de riqueza para as áreas de Floresta Atlântica conforme o regime de chuvas.

Quanto às tipologias florestais, 179 espécies (94,7\%) possuem ocorrência na Floresta Ombrófila Densa, sendo 57 (30,2\%) exclusivas. A segunda tipologia que compartilha o maior número de espécies com o Parque Natural Municipal do Curió é a Floresta Estacional Semidecidual, com 125 $(66,2 \%)$, sendo $7(3,7 \%)$ exclusivas. Com a Floresta Ombrófila Mista e a Floresta Estacional Decidual, apenas $40(21,1 \%)$ e $21(11,1 \%)$ espécies são compartilhadas, respectivamente. Do total de espécies, apenas 69 (36,5\%), são endêmicas da Floresta Atlântica, enquanto $120(63,5 \%)$ possuem ocorrência com outros biomas. O nível de endemismo (36,5\%) é inferior aos outros estudos realizados na Floresta Atlântica, que indicam taxas de endemismos entre 42 e 55\% (MORI et al., 1981; LEITÃO FILHO, 1994; THOMAZ et al., 1998; STEHMANN et al., 2009). A área de estudo, inserida em uma zona de contato entre as formações Ombrófila e Estacional, pode agregar espécies comuns a ambas e reduzir as endêmicas.

Das espécies encontradas no presente estudo, 23 foram citadas por Oliveira Filho e Fontes (2000) como supertramp, caracterizadas pelo padrão de distribuição neotropical, ocorrendo de forma ampla em todo território nacional. Outras possuem distribuição restrita, com ocorrência ou registro exclusivo do estado do Rio de Janeiro ou em poucos estados vizinhos, como: Byrsonima oblanceolata Nied., Mollinedia corcovadensis Perkins, Pradosia kulhmannii Toledo, Pseudopiptadenia inaequalis (Benth.) Rauschert, Qualea gestasiana A. St.-Hil., Tibouchina granulosa (Desr.) Cogn., Zollernia glabra (Spreng.) Yakovlev, Zollernia glaziovii Yakovlev, Tripterodendron filicifolium Radlk., Roupala longepetiolata Pohl e Psychotria appendiculata Müll. Arg. (RIBEIRO; LIMA, 2009; FORZZA et al., 2015). O endemismo e a especificidade de habitat são fatores fundamentais na determinação da raridade das espécies vegetais e entre outros fatores, como a disjunção de indivíduos de um mesmo táxon (THOMAS et al., 1998). Assim, os estudos fitogeográficos são importantes ferramentas para a classificação do status de conservação das espécies florestais, podendo fundamentar a definição das espécies prioritárias para a conservação.

A análise de agrupamento indicou a existência de cinco grupos florísticos ao nível de $25 \%$ de similaridade (Figura 2), evidenciando a baixa semelhança florística entre as áreas consideradas. As intensas variações climáticas, altitudinais e edáficas são citadas como os principais fatores ambientais que fundamentam a diferenciação florística entre fragmentos (TORRES et al., 1997; OLIVEIRA FILHO; FONTES, 2000; PEIXOTO et al., 2004) e a formação desses grupos.

O grupo A foi formado por Florestas Estacionais de Terras Baixas e uma Floresta Ombrófila de Terras Baixas, sendo as características comuns a proximidade do mar, a baixa pluviosidade e a altitude. A similaridade entre essas formações também foi constatada por Nettesheim et al. (2010) e por Peixoto et al. (2004), o que pode ser uma característica da flora no Norte do estado. O grupo B, foi composto por áreas de Floresta Ombrófila com elevada altitude, compostas por uma flora típica. Nettesheim et al. (2010) mencionaram a existência de similaridade florística para as florestas altomontanas do 
Sudeste brasileiro, mesmo havendo separação entre as áreas de maior altitude (Serra do Mar e Serra da Mantiqueira), através do vale do Rio Paraíba do Sul.

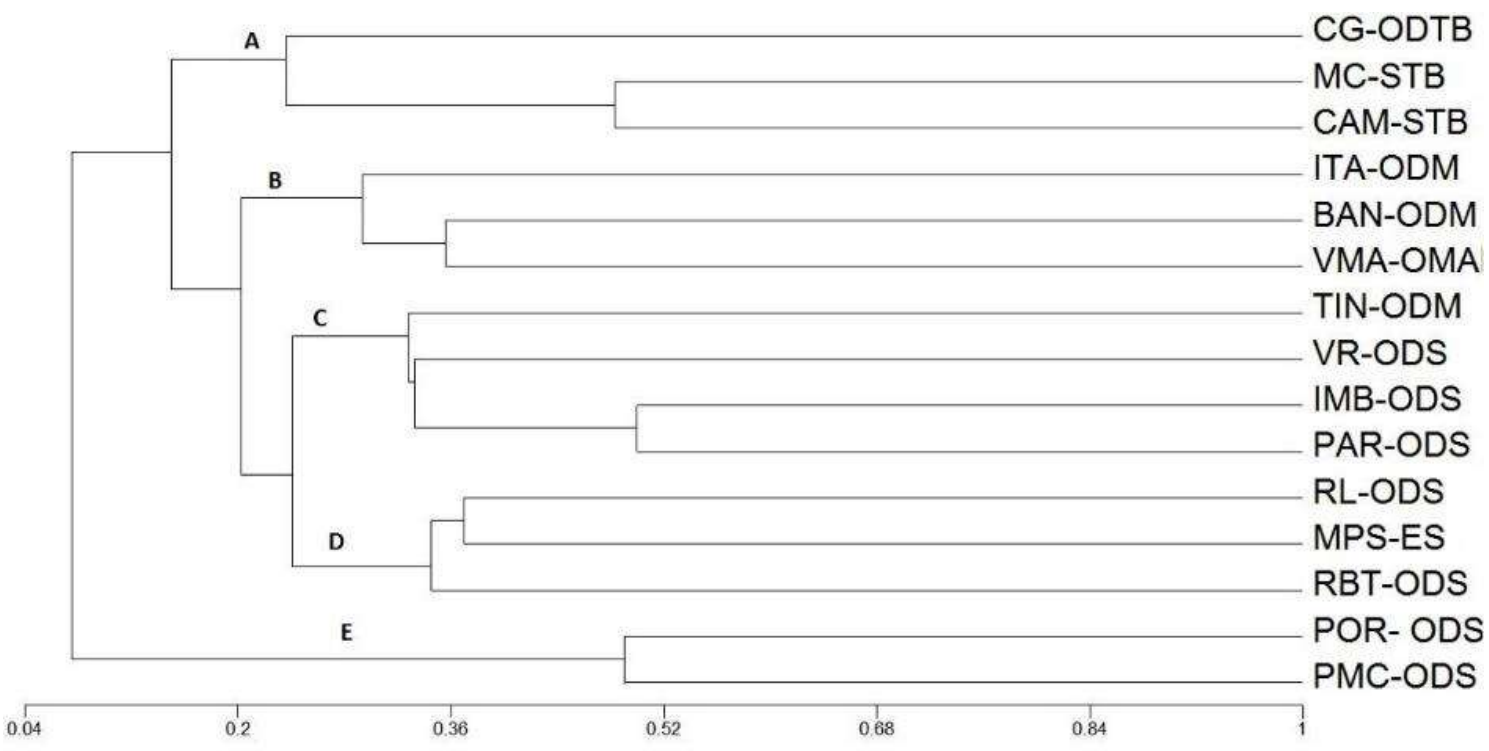

Figura 2. Dendrograma de similaridade florística formado para as florestas analisadas.

Em que: CG-ODTB = Capoeira Grande; MC-STB = Mata do Carvão; CAM-STB = Campos dos Goytacaz; ITA-ODM = Itatiaia; BAN-ODM = Bananal; VMA-OMA = Visconde de Mauá; TIN-ODM = Tinguá; VR-ODS = Volta Redonda; IMB-ODS = Imbé; PAR-PDS = Paraíso; RL-ODS = Ribeirão das Lages; MPS-ES = Médio Paraíba do Sul; RBTODS = Rio Bonito; POR-ODS = Porangaba; e PMC-ODS = Parque do Curió.

O terceiro grupo (C) foi formado por Florestas Ombrófilas Submontanas, com exceção da Reserva Biológica do Tinguá (Montana) que compôs um subgrupo. Essa diferenciação provavelmente está associada à maior altitude, que influencia a distinção da flora. O quarto grupo (D) foi formado por Florestas Ombrófilas e Estacionais Submontanas, onde a inclusão da área localizada no Médio Paraíba do Sul (MPS), classificada como Floresta Estacional, pode estar relacionada à sua proximidade com Florestas Ombrófilas, devido a influência das floras adjacentes em regiões de contato (PIANKA, 1994; NETTESHEIM et al., 2010).

A área do presente estudo está inserida no grupo (E), formado por apenas duas Florestas Ombrófilas Submontanas, apresentando elevada similaridade (50\%). A proximidade entre essas áreas deve ser ressaltada, pois a distância pode ser fator determinante na semelhança entre floras (OLIVEIRA FILHO; FONTES, 2000; PEIXOTO et al., 2004; NETTESHEIM et al., 2010). A localização dessas duas áreas na mesma bacia hidrográfica (Bacia do Rio Guandu), compondo o bloco de remanescentes florestais do Sul fluminense (ROCHA et al., 2003), pode contribuir para a elevada similaridade florística encontrada.

Os resultados obtidos corroboram a existência de grupos florísticos, similares ou distintos, de acordo com a localização geográfica, altitude e pluviosidade mencionados na literatura (OLIVEIRA FILHO; FONTES, 2000; MORENO et al., 2003; PEIXOTO et al., 2004; CARVALHO et al., 2008; NETTESHEIM et al., 2010). Essas constatações reforçam a heterogeneidade florística da Mata Atlântica e a importância das análises de agrupamento e similaridade, para a percepção de padrões florísticos. A importância da unidade de conservação do Parque Natural Municipal do Curió se torna imprescindível, conectando importantes floras e suportando elevada diversidade. Portanto, recomendase a realização de novos estudos, focados no conhecimento e conservação das regiões ecotonais, principalmente no estado do Rio de Janeiro, onde esse conhecimento ainda é escasso.

\section{CONCLUSÃO}

A análise de similaridade evidenciou a existência de cinco grupos, formados por características ambientais e composição de espécies semelhantes, demonstrando que altitude e a pluviosidade são fatores determinantes na distribuição das espécies e na composição das floras. Além disso, a elevada riqueza florística constatada no Parque Natural Municipal do Curió está fundamentada no aspecto 
fitogeográfico, uma vez que sua localização em região de ecótono, entre formações e climas, permite o compartilhamento de espécies comuns às Florestas Ombrófilas e Estacionais, ocasionando maior riqueza de espécies.

\section{AGRADECIMENTOS}

Os autores agradecem aos pesquisadores que auxiliaram na leitura do manuscrito, Felipe Cito Nettesheim, Alexandre Fernandes Bamberg de Araujo e Alexandra Pires.

\section{REFERÊNCIAS BIBLIOGRÁFICAS}

AB'SABER, A. N. Painel das interferências antrópicas na fachada atlântica do Brasil: litoral e retroterra imediata. In: Anais do II Simpósio de Ecossistemas da Costa Sul e Sudeste Brasileira. São Paulo: ACIESP, n. 71, 1990. 24 p.

AMORIM, T. A. Árvores e lianas em um fragmento florestal do sul fluminense: Relação entre variáveis ambientais e estrutura dos dois componentes lenhosos. 2012. 84 f. Dissertação (Mestrado em Ciências Ambientais e Florestais) - Universidade Federal Rural do Rio de Janeiro. Seropédica, 2012.

AMORIM; A. D.; THOMAS, W. W.; CARVALHO, A. M.; JARDIM, J. G. Floristics of the UNA biological reserve, Bahia, Brazil. In: THOMAS, W. (Ed.) The Atlantic Coastal Forests of Northeastern Brazil. New York: Memoirs of the New York Botanical Garden, p. 67-146, 2008.

APG - THE ANGIOSPERM PHYLOGENY GROUP. An update of the Angiosperm Phylogeny Group classification for the orders and families of flowering plants: APG III. Botanical Journal of the Linnean Society, v. 161, p. 105-121. 2009.

BIGARELLA, J. J. Aspectos físicos da paisagem. In: Mata Atlântica. Ed. Index/Fundação SOS Mata Atlântica. 1991. p. 63-93.

BIGARELLA, J. J. The Barreiras Group in Northeastern Brazil. Anais da Academia Brasileira de Ciências, v. 47, p. 365-393, 1975.

CAMPELLO, E. F. C. A influência de leguminosas arbóreas fixadoras de nitrogênio na sucessão vegetação em áreas degradadas da Amazônia. 1997. 120 f. Tese (Doutorado em Ciências Florestais) - Universidade Federal de Viçosa, Viçosa, 1997.

CARVALHO, F. A.; BRAGA, J. M. A.; GOMES, J. M.; SOUZA, J. S.; NASCIMENTO, M. T. Comunidade arbórea de uma Floresta de Baixada Aluvial no município de Campos dos Goytacazes, RJ. Cerne, v. 12, n. 2, p. 157-166, 2006.

CARVALHO, F. A.; NASCIMENTO, M. T.; BRAGA, J. M. A. Estrutura e composição florística do estrato arbóreo de um remanescente de Mata Atlântica submontana no município de Rio Bonito, RJ, Brasil (Mata Rio Vermelho). Revista Árvore, v. 31, n. 4, p. 717-730, 2007.

CARVALHO, F. A.; NASCIMENTO, M. T.; OLIVEIRA FILHO, A. T. Composição, riqueza e heterogeneidade da flora arbórea da bacia do Rio São João, RJ, Brasil. Acta Botanica Brasilica, v. 22, p. 929-940, 2008.

CASTRO, A. G. Levantamento florístico de um trecho de Mata Atlântica na estação ecológica de Bananal, Serra da Bocaína, Bananal, São Paulo. 2001. 63 f. (Dissertação de Mestrado em Ciências Ambientais e Florestais) - Universidade Federal Rural do Rio de Janeiro, Seropédica, 2001.

CYSNEIROS, V. C.; MENDONÇA JÚNIOR, J. O.; GAUI, T. D.; BRAZ, D. M. Diversity, community structure and conservation status of an Atlantic Forest fragment in Rio de Janeiro State, Brazil. Biota Neotropica, v. 15, n. 2, p. 1-15, 2015. 
EISENLOHR, P. V.; MELO, M. M. R. F.; IVANAUSKAS, N. M.; SOUZA, V. C.; RODRIGUES, R. R.; DUARTE, A. R.; BREIER, T. B.; UDULUTSCH, R. G. Floresta Ombrófila Densa Atlântica: bases conceituais e estudo de caso no Parque Estadual Carlos Botelho, SP, Brasil. In: Fitossociologia no Brasil: métodos e estudos de casos. Viçosa: Ed. UFV, 2011, p. 372-387.

FERREIRA JUNIOR, W. G.; SCHAEFER, C. E. G. R.; \& SILVA, A. F. Uma Visão Pedogeomorfológica sobre as Formações Florestais da Mata Atlântica. In: Martins, S.V. (Ed.). Ecologia de Florestas Tropicais do Brasil. Viçosa: Editora UFV, 2009, p. 109-142.

FORZZA, R. C.; LEITMAN, P. M.; COSTA, A. F.; CARVALHO JR., A. A.; PEIXOTO, A. L.; WALTER, B. M. T.; BICUDO, C.; ZAPPI, D.; COSTA, D. P.; LLERAS, E.; MARTINELLI, G.; LIMA, H. C.; PRADO, J.; STEHMANN, J. R.; BAUMGRATZ, J. F. A.; PIRANI, J. R.; SYLVESTRE, L.; MAIA, L. C.; LOHMANN, L. G.; QUEIROZ, L. P.; SILVEIRA, M.; COELHO, M. N.; MAMEDE, M. C.; BASTOS, M. N. C.; MORIM, M. P.; BARBOSA, M.; MENEZES, M.; HOPKINS, M.; SECCO, R.; CAVALCANTI, T. B.; SOUZA, V. C. Lista de espécies da flora do Brasil. 2015. Disponivel em: <http://floradobrasil.jbrj.gov.br> Acesso em: 22/06/2015.

GANDRA, M. F.; NUNES-FREITAS, A. F.; SCHÜTTE, M. S. Composição Florística do Estrato Arbóreo na RPPN Porangaba em Itaguaí, Estado do Rio de Janeiro, Brasil. Revista Floresta e Ambiente, v. 18, n. 1, p. 87-97, 2011.

KURTZ, B. C.; ARAUJO, D. S. D. Composição florística e estrutura do componente arbóreo de um trecho de Mata Atlântica na Estação Ecológica Estadual do Paraíso, Cachoeiras de Macacu, Rio de Janeiro, Brasil. Rodriguésia, v. 51, n. 78, p. 69-112, 2000.

LEITÃO FILHO, H. F. Diversity of arboreal species in Atlantic rain forest. Anais da Academia Brasileira de Ciências, v. 66, p. 91-96, 1994.

LEWIS, G. P.; SCHRIRE, B.; MACKINDER, B. \& LOCK, M. Legumes of the world. Londres: Royal Botanic Gardens, 2005. 577 p.

LINO C. F.; ALBUQUERQUE J. F. Mosaicos de unidades de conservação no corredor da serra do mar. São Paulo: Conselho Nacional da Reserva da Biosfera da Mata Atlântica, 2007. 96 p.

MAGURRAN, A. E. Medindo a diversidade biológica. Curitiba: Universidade Federal do Paraná, 2011. $261 \mathrm{p}$.

MCCUNE, B.; GRACE, J. B. Analysis of ecological communities. Oregon: MjM Software Design. 2002.

MORENO, M. R.; NASCIMENTO, M. T.; KURTZ, B. C. Estrutura e composição florística do estrato arbóreo em duas zonas altitudinais na Mata Atlântica de encosta da região do Imbé, RJ. Acta Botanica. Brasílica, v. 17, n. 3, p. 371-386, 2003.

MORI, S. A.; BOOM, B. M; PRANCE, G. T. Distribution patterns and conservation of eastern Brazilian coastal forest species. Brittonia, v. 33, p. 233-245, 1981.

MORLEY, R. J. Geological evolution of tropical rain forests. London: Jonh Wiley \& Sons, 2000. 362 p.

NETTESHEIM, F. C.; MENEZES, L. F. T.; CARVALHO, D. C.; CONDE, M. M. S.; ARAUJO, D. S. D. Influence of environmental variation on Atlantic Forest tree-shrub-layer phytogeography in southeast Brazil. Acta Botanica Brasilica, v. 24, n. 2, p. 369-377, 2010.

OLIVEIRA FILHO, A. T.; FONTES, M. A. L. Patterns of floristic diferentiation among Atlantic Forest in southeastern Brazil and the influence of climate. Biotropica, v. 32, n. 4, p. 793-810, 2000.

OLIVEIRA FILHO, A. T.; RATTER, J. A. Padrões florísticos das matas ciliares da região do cerrado e a 
evolução das paisagens no Brasil central durante o quaternário tardio. In: RODRIGUES, R. R.; LEITÃO FILHO, H. F. Matas ciliares: conservação e recuperação. 2 ed. São Paulo: FAPESP, 2004, p. 73-89. PEEL, M. C.; FINLAYSON, B. L.; MCMAHON, T. A. Updated world map of the Köppen-Geiger climate classification. Hydrology Earth System Sciences, v. 11, p. 1633-1644, 2007.

PEIXOTO, A. L.; ROSA, M. M. T.; BARBOSA, M. R. V.; RODRIGUES. H. C. Composição florística da área em torno da represa de Ribeirão das Lages, Rio de Janeiro, Brasil. Revista da Universidade Rural, v. 17, n. 1, p. 51-74, 1995.

PEIXOTO, A. L.; ROSA, M. M. T.; SILVA, I. M. Caracterização da Mata Atlântica. In: Manual metodológico para estudos na Mata Atlântica. Seropédica: EDUR, 2002. 120 p.

PEIXOTO, G. L.; MARTINS, S. V.; SILVA, A. F.; SILVA, E. Composição florística do componente arbóreo de um trecho de Floresta Atlântica na Área de Proteção Ambiental da Serra da Capoeira Grande, Rio de Janeiro, RJ, Brasil. Acta Botanica Brasilica, v. 18, n. 1, p. 151-160, 2004.

PEIXOTO, G. L.; MARTINS, S. V.; SILVA, A. F.; SILVA, E. Estrutura do componente arbóreo de um trecho de Floresta Atlântica na Área de Proteção Ambiental da Serra da Capoeira Grande, Rio de Janeiro, RJ, Brasil. Acta Botanica Brasilica, v. 19, n. 3, p. 539-547, 2005.

PEREIRA, I. M.; OLIVEIRA-FILHO, A. T.; BOTELHO, S. A.; CARVALHO, W. A. C.; FONTES, M. A. L.; SCHIAVINI, I.; SILVA, A. F. Composição floristica do compartimento arbóreo de cinco remanescentes florestais no Maciço do Itatiaia, Minas Gerais e Rio de Janeiro. Rodriguésia, v. 57, p. 103-126, 2007.

PIANKA, E. R. Evolutionary ecology. New York: Rarpercollins College Publishers, 1994. 249 p.

PUIG, H. Floresta Tropical Úmida. São Paulo: UNESP, 2008. 496 p.

RIBEIRO, R. D.; LIMA, H. C. Riqueza e distribuição geográfica de espécies arbóreas da família Leguminosae e implicações para conservação no centro de diversidade vegetal de Cabo Frio, Rio de Janeiro, Brasil. Rodrigésia, v. 60, n. 1, p. 111-127, 2009.

ROCHA, C. F. D.; BERGALLO, H. G.; ALVES, M. A. S.; SLUYS, M. V. A biodiversidade nos grandes remanescentes florestais do estado do Rio de Janeiro e nas restingas da Mata Atlântica. São Carlos: RiMa, 2003. 160 p.

SILVA, G. C. da; NASCIMENTO, M. Fitossociologia de um remanescente de mata sobre tabuleiros no norte do estado do Rio de Janeiro (Mata do Carvão). Revista Brasileira de Botânica, v. 24, n. 1, p. 51-62, 2001.

SMMAP - SECRETARIA MUNICIPAL DE MEIO AMBIENTE DE PARACAMBI; ITPA - INSTITUTO TERRA DE PRESERVAÇÃO AMBIENTAL. Plano de manejo do Parque natural Municipal do Curió de Paracambi. Prefeitura Municipal de Paracambi, 2010. 401 p.

SOBRINHO, F. A. P.; CHRISTO, A. G.; GUEDES-BRUNI, R. R. Fitossociologia do componente arbóreo num remanescente de Floresta Ombrófila Densa Submontana limítrofe à Reserva Biológica do Tinguá, Rio de Janeiro. Floresta, v. 40, n. 1, p. 111-124, 2010.

SOUZA, G. R. Florística do estrato arbustivo-arbóreo em um trecho de Floresta Atlântica, no médio Paraíba do Sul, município de Volta Redonda, Rio de Janeiro. 2002. 52 f. Dissertação (Mestrado em Ciências Ambientais e Florestais) - Universidade Federal Rural do Rio de Janeiro, Seropédica, 2002.

SPOLIDORO, M. L. C. V. Composição e estrutura em um trecho de floresta no médio Paraíba do Sul, RJ. 2001. 100 f. Dissertação (Mestrado em Ciências Ambientais e Florestais) - Universidade Federal Rural do Rio de Janeiro, Seropédica, 2001.

STEHMANN, J. R.; FORZZA, R. C.; SALINO, A.; SOBRAL, M.; COSTA, D. P. E.; KAMINO, L. H. Y. 
Plantas da Floresta Atlântica. Rio de Janeiro: Jardim Botânico do Rio de Janeiro, 2009. 516 p.

THOMAS, W. W.; CARVALHO, A. M. A.; GARRISON, J.; ARBELAEZ, A. L. Plant endemism in two forests in southern Bahia, Brazil. Biodiversity and Conservation, v. 7, p. 311-322, 1998.

TORRES, R. B.; MARTINS, F. R.; KINOSHITA, L. S. Climate, soil and tree flora relationships in forests in the state of São Paulo, Southestern Brazil. Revista Brasileira de Botânica, v. 20, n. 1, p. 41-49, 1997.

VELOSO, H. P.; RANGEL FILHO, A. L. R.; LIMA, J. C. A. Classificação da vegetação Brasileira adaptada a um sistema universal. Rio de Janeiro: Instituto Brasileiro de Geografia e Estatística, 1991. 